\title{
Determining Pathways and Connections Between Access to Water and High School Noncompletion Rates for Communities Along the U.S.-Mexico Border
}

\author{
Margie R. Vela \\ New Mexico State University \\ Sarah E. Lind \\ New Mexico State University \\ Paul H. Gutierrez \\ New Mexico State University
}

\begin{abstract}
Lack of access to potable water through a conveyance system impacts all aspects of modern life. Many colonias, communities in the Southwestern United States along the U.S.-Mexico border, continue to lack access to piped and treated water. This article discusses a model for the pathway from lack of access to water to lack of high school completion, including intermediary conditions impacting wellness, health, and quality of life for community members. A facilitated discussion with five environmental and public health experts who frequently work in the colonias of El Paso County, Texas (border communities that resemble the developing world), established common themes found in these communities. This process mapped the pathway from lack of access to water to noncompletion of high school for residents of the colonias. Further analysis of the pathway led to a model that describes these conditions in terms of built, cultural, human, and political capitals using the capital community framework (Emery \& Flora, 2006). The resulting model determines local community investments for advancing positive effects on the beginning, intermediary, and end conditions in the pathway, which have the capacity to positively impact education outcomes. The resulting model can be used to inform policy makers in making investment decisions for developing communities throughout the world including those that face devastation and are in the process of rebuilding sustainable infrastructure with limited financial capital.
\end{abstract}

Keywords: water, social impact of lack of access to water, water equity, educational attainment, effects of water on education

We would like to thank Dr. W. Hargrove of the University of Texas at El Paso's Center for Environmental Resource Management for facilitating an intriguing conversation for this study and Mr. Edward Stokes for sharing unpublished data. We would also like to thank Dr. C. Gard of New Mexico State University's Economics, Applied Statistics, and International Business Department for assistance with the statistical data analysis and editing and Jordan Woodbury and Daniel Zaragoza for a concerted effort in data mining for colonia data. Finally, we acknowledge the New Mexico State University Research Initiative for Scientific Enhancement and the Water Resource Research Institute for unwavering support and professional training. This work has been presented as an abstract for oral presentation at the Society for the Advancement for Hispanics, Chicanos, and Native Americans for Science annual meeting 2017. This work was funded by the National Institutes of Health (R25GM061222). 


\section{Introduction}

The United Nations Educational, Scientific, and Cultural Organization's World Water Assessment Programme (2006) asserted access to water affects access to education in developing communities around the world. Physical access to water, water quality, economic capacity to treat water, and cultural values, beliefs, and practices prescribe community norms that often exacerbate conditions constraining academic achievement. Similarly, many communities in the United States, colonias found in the U.S.-Mexico border region, resemble the conditions of the developing world, lacking access to piped potable water. The high school completion rates of these communities, when compared to the national average, suggest that residents of the colonias experience barriers to educational attainment; however, current academic literature does not address the relationship between access to water and educational attainment for these communities. This study developed and examined the connections between lack of access to water and high school completions rates and determines the most impactful capital investments for reducing high school noncompletion rates in rural communities.

The Cranston-Gonzalez National Affordable Housing Act (1990) is the federal guideline for defining the colonias. The legislation uses five criteria to designate the colonia status for federal purposes:

The term colonia means any identifiable community that

(A) is in the State of Arizona, California, New Mexico, or Texas;

(B) is in the United States-Mexico border region;

(C) is designated by the State or county in which it is located as a colonia;

(D) is determined to be a colonia on the basis of objective criteria, including lack of potable

water supply, lack of adequate sewage systems, and lack of decent, safe, and sanitary

housing; and

(E) was in existence and generally recognized as a colonia before the date of the enactment of this Act. (Title IX, Section 916[e][1])

This act determines the border region as the geographical area within 150 miles of the U.S.-Mexico border and excludes communities within any standard metropolitan statistical area with a population exceeding 1,000,000 (Cranston-Gonzalez National Affordable Housing Act, 1990).

Available data for statistical analysis of the colonias are often limited. The communities included in this study are located in El Paso County, Texas, which is home to over 200 colonias; however, only 16 are designated census blocks, also referred to as census data places by the U.S. Census Bureau. Designation of colonias by the State of Texas also requires the community to hold unincorporated status; as such, detailed data, local representation, and record keeping are often absent.

Many of the residents of these communities lack access to piped, potable water delivered through a municipal conveyance system. This lack of access to water has a profound impact on quality of life and educational attainment for all community members. This study used qualitative methods to define the pathway between educational attainment, specifically acquisition of a high school diploma, and access to potable water through a municipal conveyance system. Census data for 16 colonias in El Paso County for 2015, listed in Table 1, were analyzed for high school completion rates and were compared to national averages.

Census data for 2015 show that current Hispanic graduation rates are consistent with historic trends. Graduation rates for Hispanic students are conventionally lower than the national average (Vela \& Gutierrez, 2017). The effects of this can be seen for the Hispanic population throughout the 
education pipeline. Figure 1 illustrates the completion rates of the Hispanic population at the high school level and various levels of higher education (Stoker, 2016). Nationwide, the high school completion rate for Hispanics was $66.7 \%$ compared to the U.S. average of $86.7 \%$ for the population 25 years and older.

Table 1. Demographics for Colonias Included in the Study

\begin{tabular}{lccccc}
\hline Texas Community & Population & Hispanics & Males & Females & Median Age (y) \\
\hline Agua Dulce & 2,926 & 2,902 & 1,424 & 1,502 & 25.4 \\
B \& E Estates & 698 & 698 & 405 & 293 & 22.1 \\
Butterfield & 83 & 83 & 49 & 34 & 46.9 \\
Canutillo & 6,110 & 5,037 & 3,376 & 2,734 & 30 \\
Clint Town & 820 & 698 & 409 & 411 & 43.6 \\
Cochran County & 2,993 & 1,679 & 1,519 & 1,474 & 34.9 \\
Flor del Rio & 139 & 139 & 79 & 60 & 28.3 \\
Homestead Meadows North & 4,564 & 4,230 & 2,324 & 2,240 & 28.1 \\
Homestead Meadows South & 5,811 & 5,761 & 2,477 & 3,334 & 34.4 \\
Las Quintas & 2,251 & 2,251 & 930 & 1,321 & 24.8 \\
Morning Glory & 423 & 385 & 221 & 202 & 30 \\
Panorama Village & 2,013 & 118 & 921 & 1,092 & 56.4 \\
Prado Verde & 262 & 246 & 118 & 144 & 39.4 \\
Rio Vista & 1,174 & 194 & 584 & 590 & 30.7 \\
Tornillo & 1,367 & 1,367 & 717 & 650 & 28.3 \\
Westway & 3,868 & 3,766 & 1,865 & 2,003 & 24.6 \\
\hline
\end{tabular}

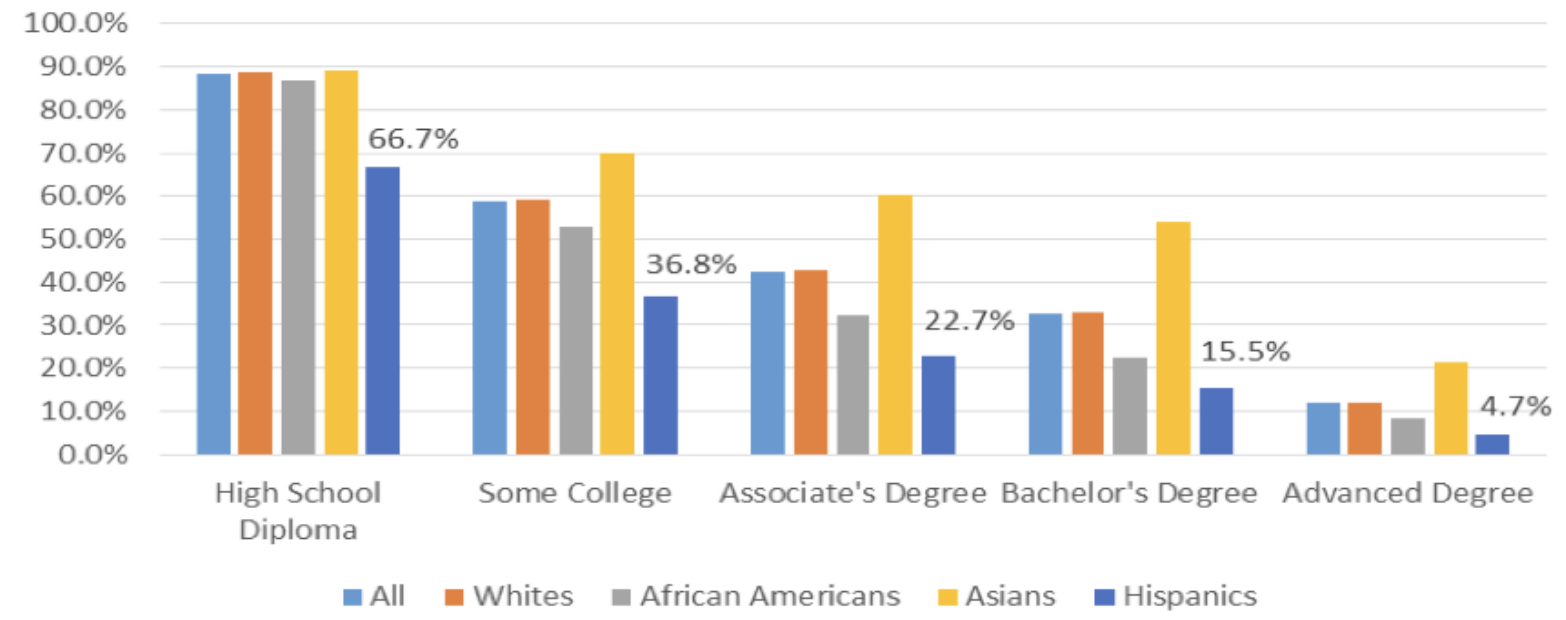

Figure 1. Educational Attainment by Race and Ethnicity for Persons 25 Years and Older in 2015. Adapted from Stoker (2016). 
The high school completion rate for colonia residents for 2015 for persons 25 years and older was $58.8 \%$, which was $27.9 \%$ lower than the national average and $7.9 \%$ lower than the national Hispanic high school completion rate, disparities that are consistent with historic trends. Figure 2 shows the graduation rates for each colonia, as well as the mean high school completion rate for all colonias included in this study, the national high school completion rate for Hispanics and the national high school completion rate for the United States.

\section{High School Graduation Rates}

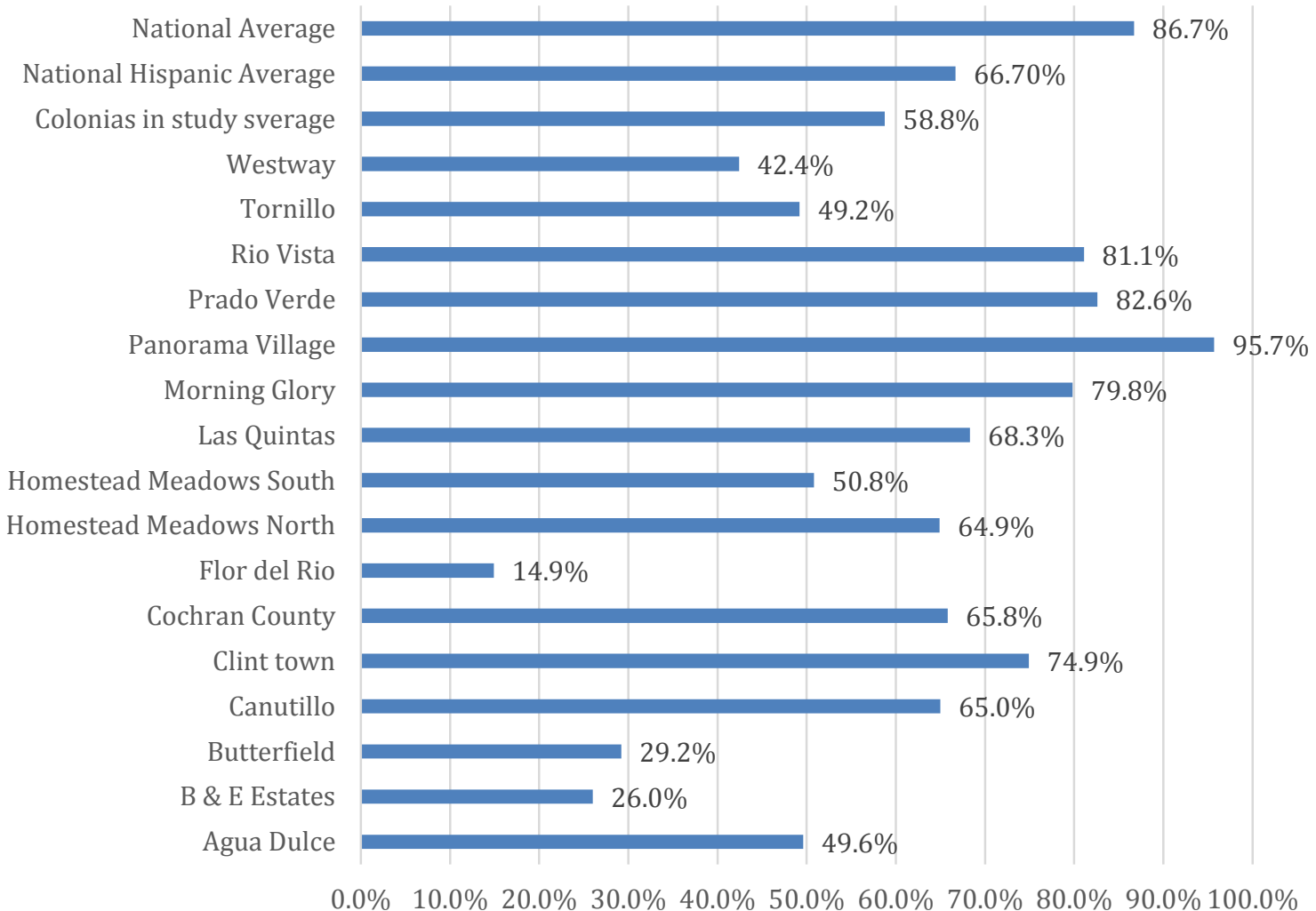

Figure 2. High School Graduation Rates for Persons 25 Years and Older for 2015. Using data from U.S. Census Bureau's American Fact Finder (https://factfinder.census.gov/faces/nav/jsf/pages/community_facts.xhtml) 


\section{Methodology}

A panel of experts, composed of researchers with experience and expertise in colonias, convened to discuss and determine possible pathways for the relationship between lack of access to potable water, including limited access to water, and noncompletion of high school for residents of these communities. The discussion took place at a land-grant institution of higher education in the same region as the communities included in the study. The exercise was facilitated by an expert scientist who frequently works in the colonias and leads similar discussions for designing research projects. Five researchers of environmental science with experience and expertise in the colonias were involved in the discussion.

Lack of access to water was defined using three conditions: (a) no piped water into the home, (b) limited quantities of water piped into the home, or (c) poor-quality water piped into the home. The pathway identified by this team was further analyzed and organized by the authors. The conclusion was drawn by integrating the capital community framework by Emery and Flora (2006) into the original pathway diagram by grouping the themes that emerged from the discussion into four categories: built capital, human capital, political capital, and cultural capital to define the capital investments affected by access to water. These capitals impact intermediary conditions that intensify barriers to high school completion in the colonias.

\section{Defining the Problem}

The expert panel determined the conditions that ensue from the lack of access to water in the community may directly impact educational attainment levels, exacerbate conditions that directly impact educational attainment levels, or intensify conditions that negatively impact conditions affecting educational attainment. Therefore, five intermediary levels of impact were identified. The artifact in Figure 3 resulted from the discussion. The electronic version is illustrated in Figure 4.

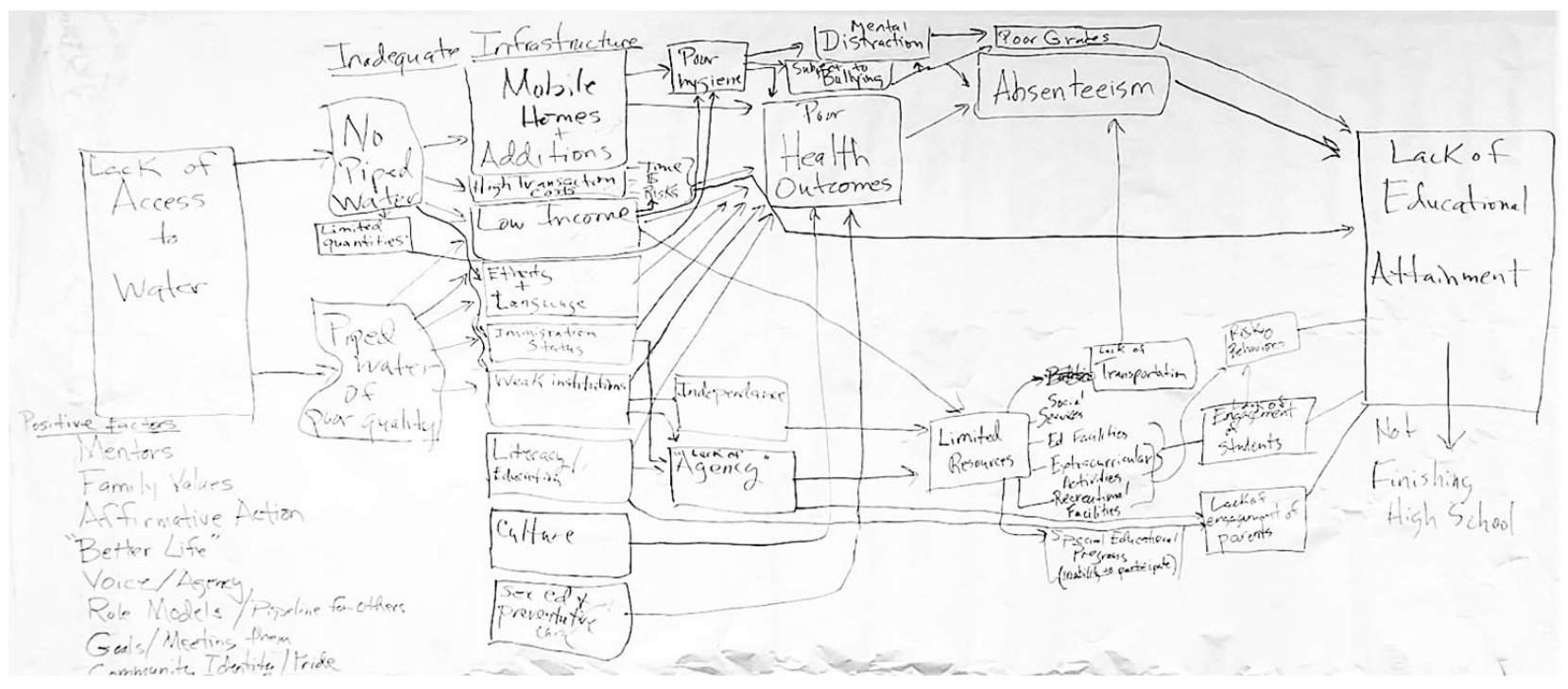

Figure 3. Artifact Produced From Expert Panel Discussion Regarding the Lack of Access to Water in the Colonias and the Effect of This on Educational Attainment in These Communities 


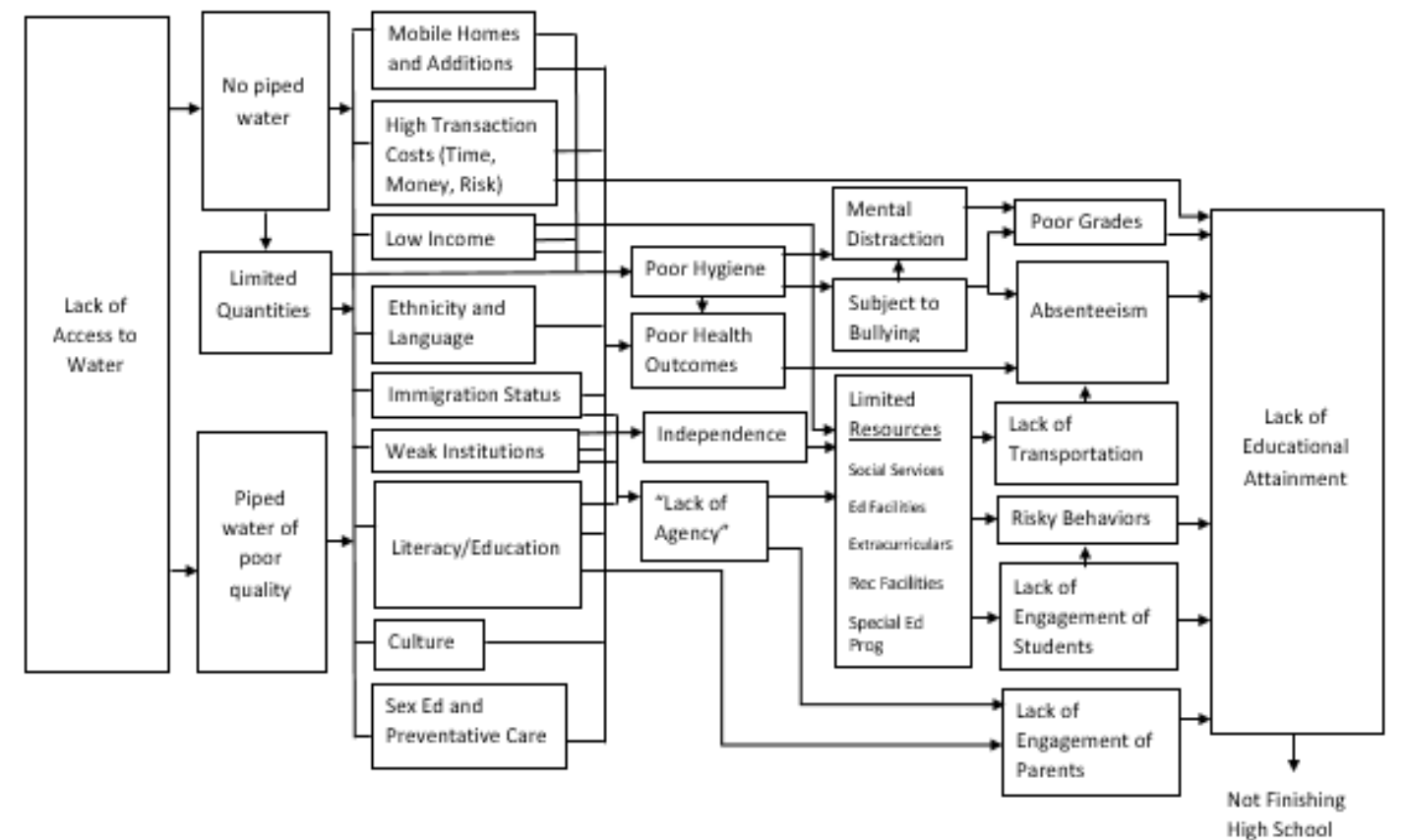

Figure 4. Electronic Version of Pathway Diagram Produced From Expert Panel Discussion Regarding the Lack of Access to Water in the Colonias and the Effect of This on Educational Attainment in These Communities

\section{Results}

The resulting pathway diagram illustrates the intermediary conditions and factors from lack of access to water through lack of educational attainment or not acquiring a high school diploma. Elements such as inadequate housing, high transportation costs, low income, lack of diversity, immigrations issues, weak institutions, literacy and education, culture, and sexual education, and preventive care are often found in colonias. Observations of the panel established during field work suggest these conditions and the impact they have on their communities are related and possibly intensified by lack of access to water.

The remainder of the pathway is reflected by an interconnection of circumstances found in the community. The preconditions elicit additional situations including: poor hygiene and health outcomes for individuals in the community, lack of agency or power to incite change, and a sense of independence from municipal services and regulations. These circumstances, along with some of the aforementioned preconditions, elicit opportunities for students to become victims of bullying or experience mental distraction in the classroom. Additionally, resources such as social services, transportation, and others are frequently difficult to access within communities that lack potable water. These conditions have negative impacts on the quality of life of community members and may increase incidents of poor academic achievement/low grades, absenteeism, and engagement of teens in high-risk behaviors, while decreasing school engagement for both parents and students. The anthology of conditions found in the community provoke a higher dropout rate, resulting in a much lower rate of high school completion for residents of the colonias. 


\section{Discussion}

\section{Rural Development and the Capital Community Framework}

The definition of rural development used in this study is designing and effecting social and economic interventions with the purpose of promoting the self-sustainability of a community with a population of 50,000 or fewer residents. This approach to rural development considers development in a holistic manner. Decision making in rural communities has a strong dependence on the culture of the community and the resources that are readily available for implementation of interventions and execution of decisions (Green \& Zinda, 2013). Social and economic dynamics found in communities are highly dependent on the established formal and informal rules and institutions, as well as the resources, geographic location, and human capital accessible to individuals within the community and the greater community. These considerations are the precursors for place-based policy making that impacts quality of life for residents (Johnson, 2013).

Flora and Flora (2008) outlined considerations for sustainable rural development in the capital community framework. Seven distinct types of capital are defined in this work: (a) built capital, (b) cultural capital, (c) human capital, (d) financial capital, (e) political capital, (f) natural capital, and (g) social capital. The community capitals, shown in Figure 5, are interdependent and often overlap.

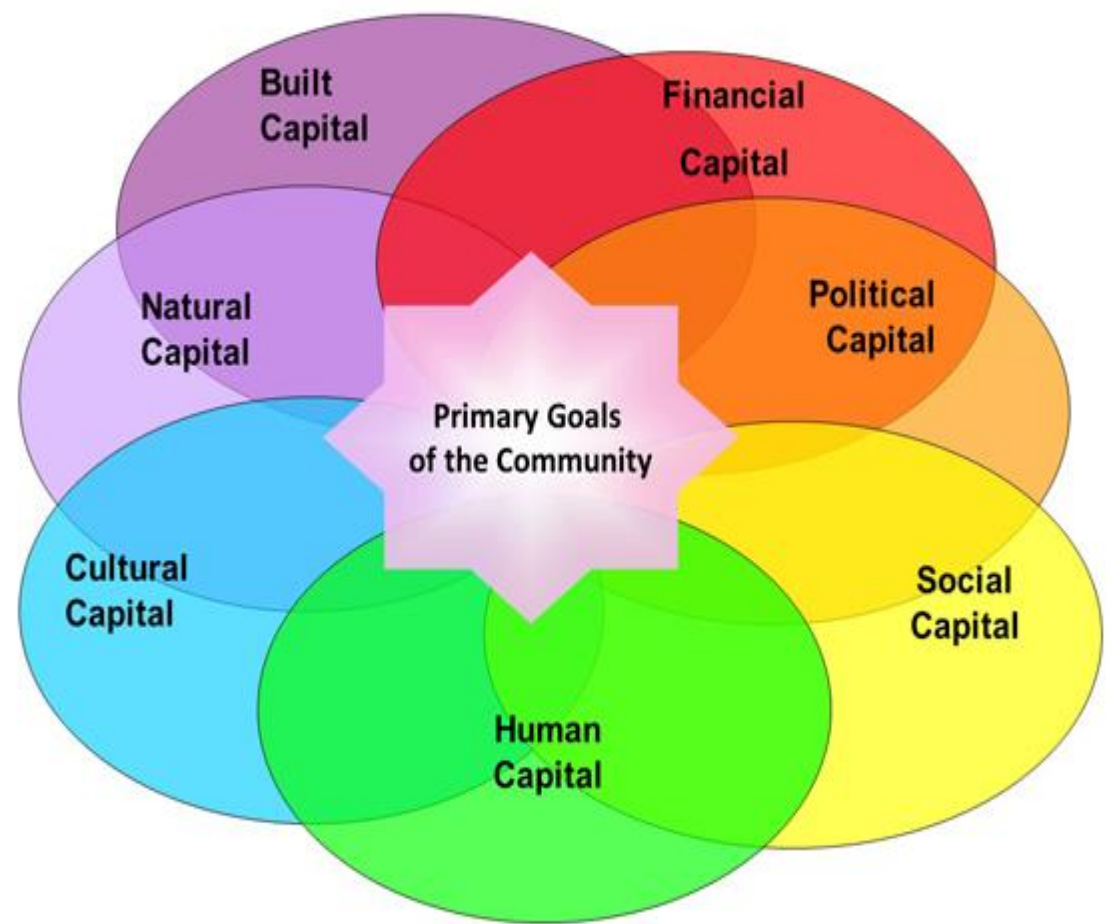

Figure 5. Capital Community Framework Used to Categorize the Effects of Lack of Access to Water on the Community for This Study. Adapted from "Spiraling-up: Mapping Community Transformation With Community Capitals Framework," by Emery, M., \& Flora, C., 2006, Community Development: Journal of the Community Development Society, 37, p. 21. Copyright 2006 by the Community Development Society. 
Investments, interventions, initiatives, and projects regularly impact more than capital, and the development of one capital has effects on other capitals. This complex system provides the foundation for the approach of pathway from lack of access to potable water to acquisition of the high school diploma. The purpose of this study was to examine the pathway and determine the most impactful capital investments for reducing high school noncompletion rates in rural communities.

Figure 6 explores the pathway for improving conditions in terms of built capital, cultural capital, human capital and political capital as intermediaries in the pathway. In theory, improvements in access to water has the potential to impact the capitals, as development of communities is highly dependent on access to potable water (Kleemeier, 2012; Matshe, Moyo-Maposa, \& Zikhali, 2013). This indirectly impacts additional intermediary conditions that have the potential to improve high school completion rates.

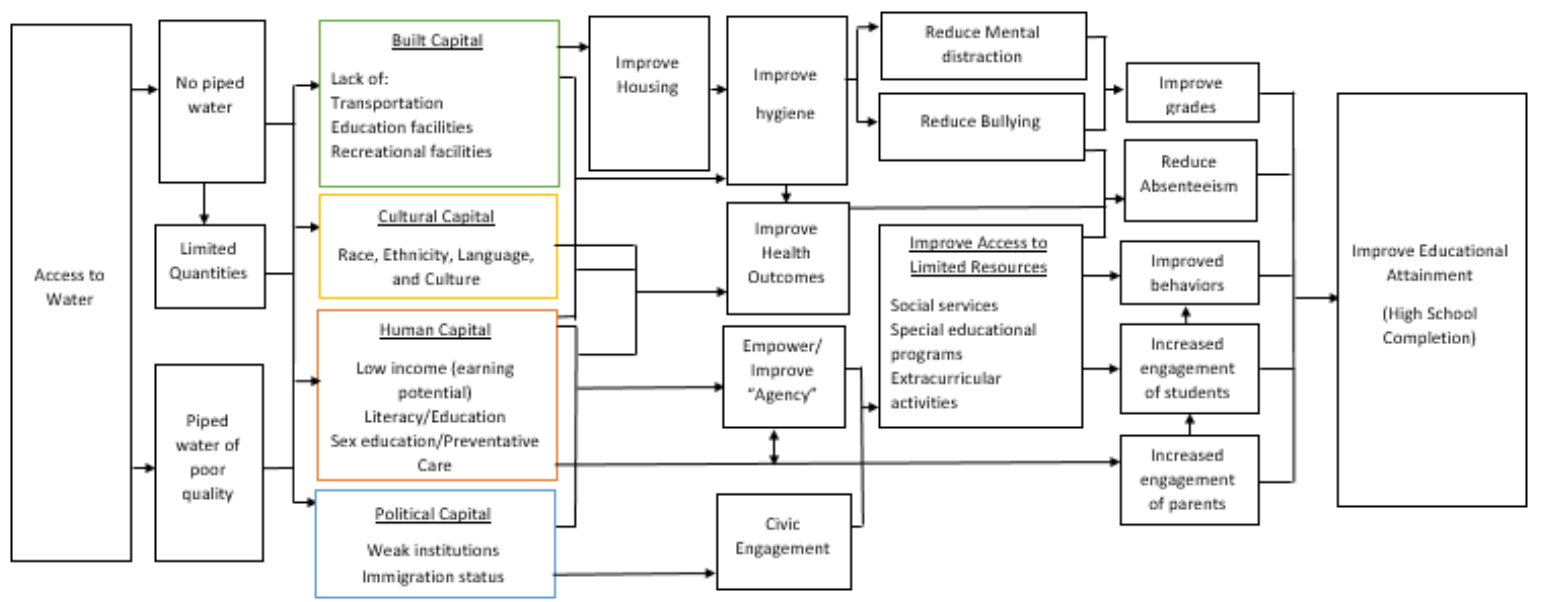

Figure 6. Pathway Diagram That Illustrates the Proposed Improvements to Community Capitals for Improving Intermediary Conditions Impacting High School Completion Rates for Youth in the Colonias (Produced by Integrating the Diagram Created by the Expert Panel)

\section{Built Capital}

Built capital refers to the infrastructure found within the community (Flora \& Flora, 2008). The observations made by members of the expert panel suggest colonias often lack infrastructure to support transportation and educational and recreational facilities. As a result of these deficiencies, students are often bussed to school in a nearby town or city. A yellow school bus may be the only form of public transportation afforded to students, making it difficult to get around town or to remain on school grounds after school to participate in extracurricular activities. Investment in transportation to promote student engagement in extracurricular activities would stand to improve educational outcomes, seeing as engagement in such activities improves educational success (Bradley \& Greene, 2013; Finn \& Rock, 1997).

Another observation by expert panelists reveals that colonias often lack recreational services and facilities, which can leave students void of constructive and structured activities in which to engage after school and on weekends. Investments in these facilities result in constructive activity for youth, deterring their engagement in risky behavior, which has a strong inverse relationship with academic success (Bradley \& Greene, 2013). Additionally, investment in recreational facilities would stand to 
increase physical activity for youth in the community. Iannotti, Kogan, Janssen, and Boyd (2010) reported that youth who are physically active have "positive physical and social health indicators including perceived health status, self-image, quality of life, and quality of peer relationships" (para. 6).

Moreover, limited access to potable water deters rural development and has negative impacts on life expectancy, income-generating activities, and the development of small enterprises, among other factors (Kleemeier, 2012; Matshe et al., 2013). As such, lack of development in these communities can also result in inadequate housing. Unsafe or unsanitary housing is problematic to proper hygiene and healthy living (Bonnefoy, 2007). This has the potential to negatively impact the cognitive, social, and physical development of young people (Bartlett, 1998). Recent studies show that students who participate in $4-\mathrm{H}$, a program that purposes to support cognitive, social, and physical development for youth, are more likely to graduate from high school and less likely to engage in risky behaviors (Lerner \& Lerner, 2017). Thus, investment in such facilities mitigates negative effects on youth development and is expected to have positive effects on the educational outcomes for students.

\section{Cultural Capital}

Cultural capital includes traditions and language and is a reflection of people's perceptions of the world and how communities and community members act within it (Emery \& Flora, 2006). Colonia populations are largely Hispanic and are located on the U.S.-Mexico border. According to a study by the Federal Reserve Bank of Dallas (2015), there are 2,294 colonias in Texas, which are home to 500,000 residents. While $96 \%$ of colonia residents are Hispanic, mostly of Mexican American decent, $66 \%$ of adults and $94 \%$ of youth are U.S. citizens (Federal Reserve Bank of Dallas, 2015). These characteristics have profound effects on the traditions and social norms found in the communities.

Additional observations made by individual panelists further define the community culture. One such observation is that the majority of homes in colonias accommodate at least one undocumented family member. Most households are Spanish-speaking homes, and many residents' first language is Spanish. Strong ties to Mexico found along the southern U.S. border result in a rich blended culture that embodies the traditions, values, and social norms of Mexican culture and American influences. The unique geography and culture often lack diversity, and cultural barriers can hinder the ability of community members to clearly communicate with healthcare providers and social advocates, impeding health literacy in for many residents. Expert panelists' observations suggest this often results in compromised health outcomes for communities along the border. The pathway diagram suggests that poor health increases absenteeism, which is a risk indicator for dropping out of school for teens living in these communities.

As suggested by Cooper (2009), sustainable water improvements require researchers, scientists, and policy makers to consider solutions that respect and understand cultural and traditional practices. Water enriches cultural capital in communities when solutions to the issue are culturally sensitive. One example of a high-impact, culturally relevant initiative in the colonias is the Colonias Project. This intervention draws on outreach workers called promotoras to increase health literacy through a train-the-trainer approach (Olney, Warner, Reyna, Wood, \& Siegel, 2007). This intervention is an example of investment in cultural and human capital. It promotes the unique and strong culture and traditions of community members and invests in the health literacy development of these residents. This approach is the embodiment of cultural competence, which effectively addresses the sociocultural barriers that increase disparities in many colonia communities (Betancourt, Green, Carrillo, \& Ananeh-Firempong, 2016). Investments in cultural capital have the potential to overcome 
sociocultural barriers and improve conditions in the colonias found within the educational attainment pathway, including improving access to safe drinking water, while embracing the unique traditions and values of the U.S.-Mexico border.

\section{Human Capital}

Human capital refers to the collective abilities and skills possessed by community members that contribute to individual and societal capacity to acquire resources (Emery \& Flora, 2006).

Characteristics — such as low income and earning potential, limited literacy and education, and lack

of sex education and preventive care-observed in colonia communities reveal a substantial disparity in human capital. Lack of rural development in communities that do not have access to a reliable source of potable water results in disparities in employment options and often perpetuates low earning potential in the community. Further, disparity in literacy rates and educational attainment levels are proliferated without investment in human capital (Bradley \& Greene, 2013).

Relegated investment in human capital results in a cycle of poverty that is difficult to disrupt. Historically, lack of capacity to acquire resources perpetuates a lack of agency within the community. This engenders limited resources, restricting the ability to achieve desired outcomes including the acquisition of facilities and services that promote student and parent engagement in education (Kabeer, 1999). Conventional research in this area has determined that many of the characteristics found in homes located in colonias are risk factors for low academic achievement (Finn \& Rock, 1997). Finn and Rock recognized that risk factors are often exacerbated by risky behaviors, which are incited by the individual and create additional barriers for academic success including academic disengagement. Subsequently, disengagement from academic activity is a risk factor for early sexual activity (Barnet, Arroyo, Devoe, \& Duggan, 2004), leading to teenage pregnancy. This disproportionately affects the dropout rates for girls, as two thirds of teenage mothers who give birth will not complete their high school education (Moore \& Osho, 2017). This is one of many examples that can be reversed with adequate investment in human capital. The complexity of human development and the consequences for its neglect require attention and resources to improve educational achievement in the colonias.

\section{Political Capital}

Political capital is the community's ability to access power to effect change (Emery \& Flora, 2006). Access and development of political influence, organizations, resources, power brokers, and individual and collective agency are evidence of political capital. Although the federal designation for colonias does not specify status, Texas requires unincorporated status for its colonia designation (Matthiesen, 1997). As such, these communities lack local political representation, resulting in weak institutions, which promotes inequity of resources and perpetuates poverty (Brady 2009; Brady, Blome, \& Kleider, 2016; Brady \& Sosnaud, 2010). It has been recognized that diminished political capital results from insufficient political participation attributed to deficient socialization for manifesting the skills necessary for political activity (Cho, 1999).

As such, "lack of agency" for the community and its members is also unveiled in the school system when mistrust of government and the education system impacts student success (Wainer, 2004). This decreases the rates at which parents are involved and engaged in government institutions, including the schools providing education to their children. Disengagement of parents negatively impacts retention and matriculation at every level of a student's academic journey (Carreón, Drake, $\&$ Barton, 2005), once again impacting the educational attainment of youth in the colonias. 
Moreover, political scientists have long proposed political alienation, as these communities experience, can foster a strong resistance to civic engagement, government regulation, and political institutions within the community. However, the community could benefit in various ways from strengthening political capital (Finifter, 1970). Colonias in Texas are void of this capital leaving the community with few options for securing infrastructure necessary to improve conditions for high school students for their successful retention, matriculation, and graduation from high school. Investment in political capital has the potential to empower residence of the colonias, prospering the community and its members in many ways.

\section{Conclusion}

Water is life. This commonly used idiom rings true for human life and for the life of a community. Access to potable water impacts the quality of life for individuals and determines sustainability for communities. Sustainable development requires basic infrastructure including water conveyance and treatment systems. When a community lacks this basic need, developers refrain from investing in the community, making it difficult to gain access to services that are desirable for community members to live healthy lifestyles and high school students to succeed in the education system. Academic success impacts financial capacity and has the potential to improve quality of life. Thus, understanding how investment in potable drinking water impacts the academic achievement of young people living in the community is compulsory for establishing healthy and sustainable communities.

Five colonia experts, through a facilitated process for discussion and interaction, discovered a unique pathway diagram from access to potable water to high school completion rates for students living in West Texas colonias. The model was created by sharing personal interactions, relationships, experiences, and observations of the researchers who convened for this discussion. The emerging model was based on dynamics unique to time and place. As communities evolve, changes to the pathway diagram will ensue. These dynamics are important to consider as policy makers decide how to invest in the colonias. Therefore, the model should be considered a living document in need of modification as changes are observed in the national, state, and local landscapes.

Future research should examine the relationships between high school students, their communities, their access to water, and their academic performance. A thorough examination of these relationships will serve to test the validity of the pathway model and discover the metrics that define existing relationships between the conditions described in the model. The results of this study will be used in research design for future studies investigating the relationship for access to water and educational attainment in the colonia communities in the Southwest United States.

\section{References}

Bartlett, S. (1998). Does inadequate housing perpetuate children's poverty? Childhood, 5, 403-420

Barnet, B., Arroyo, C., Devoe, M., \& Duggan, A. K. (2004). Reduced school dropout rates among adolescent mothers receiving school-based prenatal care. Archives of Pediatrics \& Adolescent Medicine, 158, 262-268. doi:10.1001/archpedi.158.3.262

Betancourt, J. R., Green, A. R., Carrillo, J. E., \& Ananeh-Firempong, O. (2003). Defining cultural competence: A practical framework for addressing racial/ethnic disparities in health and health care. Public Health Reports, 118, 293-302. doi:10.1093/phr/118.4.293

Bradley, B. J. \& Greene, A. C. (2013). Do health and education agencies in the United States share responsibility for academic achievement and health? A review of 25 years of evidence about 
the relationship of adolescents' academic achievement and health behaviors. Journal of Adolescent Health, 52, 523-532. doi:10.1016/j.jadohealth.2013.01.008

Brady, D. (2009). Rich democracies, poor people: How politics explain poverty. doi:10.1093/acprof:oso/9780195385878.001.0001

Brady, D., Blome, A., \& Kleider, H. (2016). How politics and institutions shape poverty and inequality. In D. Brady, \& L. M. Burton (Eds.), The Oxford handbook of the social science of poverty (pp. 117-140). New York, NY: Oxford University Press. doi:10.1093/oxfordhb/9780199914050.013.7

Brady, D. \& Sosnaud, B. (2010). The politics of economic inequality. In K. T. Leicht \& J. C. Jenkins (Eds.), Handbook of politics: Handbooks of sociology and social research, (pp. 521-541). New York, NY: Springer. doi:10.1007/978-0-387-68930-2_28

Bonnefoy, X. (2007). Inadequate housing and health: An overview. International Journal of Environment and Pollution, 30, 411-429. doi:10.1504/IJEP.2007.014819

Carreón, G. P., Drake, C., \& Barton, A. C. (2005). The importance of presence: Immigrant parents' school engagement experiences. American Educational Research Journal, 42, 465-498. Retrieved from https://scholars.opb.msu.edu/en/publications/the-importance-of-presenceimmigrant-parents-school-engagement-ex-3

Cho, W. K. T. (1999). Naturalization, socialization, participation: Immigrants and (non-)voting. The Journal of Politics, 61, 1140-1155. Retrieved from http://www.u.arizona.edu/ jag/POL596A/tamcho.pdf

Cooper, J. (2009). Preliminary overview of current research and possible research priorities: Small community drinking water supplies. In Institute of Medicine (Ed.), Global environmental health: Research gaps and barriers for providing sustainable water, sanitation, and hygiene services (pp. 81-87). Washington, DC: National Academies Press. Retrieved from https://www.ncbi.nlm.nih.gov/books/NBK50774/

Cranston-Gonzalez National Affordable Housing Act, 42 U.S.C.A. § 916 (1990).

Emery, M., \& Flora, C. (2006). Spiraling-up: Mapping community transformation with community capitals framework. Community Development: Journal of the Community Development Society, 37, 19-35. Retrieved from https://www.uvm.edu/rsenr/rm230/costarica/Emery-Flora2006.pdf

Federal Reserve Bank of Dallas. (2015). Las colonias in the 21st century: Progress along the TexasMexico border. Retrieved from https://www.dallasfed.org/assets/documents/cd/pubs/lascolonias.pdf

Finifter, A. W. (1970). Dimensions of political alienation. American Political Science Review, 64, 389410. Retrieved from https://www.cambridge.org/core/journals/american-political-sciencereview/article/dimensions-of-political-alienation/101DAB41ECAC17991029A27B79CDF6EB

Finn, J. D., \& Rock, D. A. (1997). Academic success among students at risk for school failure. Journal of applied psychology, 82, 221-234. doi:10.1037/0021-9010.82.2.221

Flora, C. B., \& Flora, J. L. (2008). Rural communities: Legacy and change (3rd ed.). Boulder, CO: Westview Publisher.

Green, G. P., \& Zinda, J. A. (2013). Rural development theory. In G. P Green (Ed.), Handbook of rural development (pp. i-ii) Cheltenham, United Kingdom: Edward Elgar. 
Iannotti, R. J., Kogan, M. D., Janssen, I., \& Boyd W. F. (2010). Patterns of adolescent physical activity, screen-based media use, and positive and negative health indicators in the U.S. and Canada. Journal of Adolescent Health, 44, 493-499. doi:10.1016/j.jadohealth.2008.10.142

Johnson, T. G. (2013). Rural policy. In J. P. Green (Ed.), Handbook of rural development (pp. 42-55). Northampton, MA: Edward Elgar.

Kabeer, N. (1999). Resources, agency, achievements: Reflections on the measurement of women's empowerment. Development and Change, 30, 435-464

Kleemeier, E. (2012, May 17). Poverty and rural water [Blog post]. Retrieved from http://blogs.worldbank.org/water/poverty-and-rural-water

Lerner, R. A., \& Lerner, J. V.(2017). The Positive development of youth: Findings from the first seven years of the 4-H study of positive youth development. Retrieved from http://ase.tufts.edu/iaryd/documents/4HPYDStudyWave7.pdf

Matshe, I., Moyo-Maposa, S., \& Zikhali, P., (2013). Water poverty and rural development: Evidence from South Africa. African Journal of Agricultural and Resource Economics, 8,136-156.

Matthiesen, J. (1997). What now for the Texas colonias. New Mexico Law Review, 27, 1-31. Retrieved from http://digitalrepository.unm.edu/nmlr/vol27/iss1/2

Moore, A. N., \& Osho, G. S. (2017). An assessment of adolescent pregnancy and social risk factors: Evidence from agencies and organizations in the juvenile justice system. International Journal of Social Work, 4, 1-14. doi:10.5296/ijsw.v4i2.10331

Olney, C. A., Warner, D. G., Reyna, G., Wood, F. B., \& Siegel, E. R. (2007). MedlinePlus and the challenge of low health literacy: Findings from the Colonias project. Journal of the Medical Library Association, 95, 31-39. Retrieved from https://www.ncbi.nlm.nih.gov/pmc/articles/PMC1773027/

Stoker, E. (2016, October). Data, demographics, y un poquito mas: The importance of the Latinos in agriculture mission. In E. W. Romero (Co-founder and Organizer), Latinos in agriculture. Keynote presentation at the annual meeting for the Latinos in Agriculture, Grapevine, Texas.

Vela, M., \& Gutierrez, P. (2017). The Hispanic population and Hispanic serving institutions. eJournal of Education Policy. Retrieved from https://nau.edu/COE/eJournal/_Forms/fall2017/Vela_Gutierrez/

Wainer, A. (2004). The new Latino South and the challenge to public education: Strategies for educators and policymakers in emerging immigrant communities. Retrieved from ERIC database. (ED502060)

United Nations Educational, Scientific, and Cultural Organization's World Water Assessment Programme. (2006). Water: A shared responsibility: U.N. World Water Development Report 2. Retrieved from http://unesdoc.unesco.org/images/0014/001444/144409E.pdf

The Journal of Social Change, sponsored by Walden University, welcomes manuscripts focusing on interdisciplinary research in social change that improves the human condition and moves people, groups, organizations, cultures, and society toward a more positive future.

Walden University Publishing: http://www.publishing.waldenu.edu 